\title{
Design and Simulation of a Novel Dual Band Microstrip Antenna for LTE-3 and LTE-7 Bands
}

\author{
Abdullah Al Hasan \\ Electronic and Telecommunication \\ Engineering \\ International Islamic University \\ Chittagong \\ Chittagong, Bangladesh
}

\author{
Mohammad Shahriar Siraj \\ Electronic and Telecommunication \\ Engineering \\ International Islamic University \\ Chittagong \\ Chittagong, Bangladesh
}

\author{
Muhammad Mostafa Amir Faisal \\ Electronic and Telecommunication \\ Engineering \\ International Islamic University \\ Chittagong \\ Chittagong, Bangladesh
}

\begin{abstract}
Long Term Evolution (LTE) is currently being used in many developed countries and hopefully will be implemented in more countries. An antenna operating in LTE-3 band can support global roaming in ITU Regions 1 and 3, Costa Rica, Brazil and partially in some Caribbean countries and antenna operating in LTE-7 band are appropriate for global roaming in ITU regions 1,2 and 3. An antenna operating at both the bands will make the place taken by the antenna in a device into half and allow roaming in all the regions mentioned above. The geometry of the current available antenna operating in LTE3 and LTE-7 bands has a considerably large size. A dual band microstrip antenna operating in LTE-3 and LTE-7 bands is proposed in this work with notable size reduction. The proposed antenna simulation shows resonant frequencies at $1.88 \mathrm{GHz}$ and 2.55GHz with return loss below -10dB that covers both LTE-3 and LTE-7 bands. Design and simulation of the proposed antenna is done by IE3D Zeland software. This proposed antenna is suitable for global roaming in ITU regions 1, 2 and 3, which cover most of the world telecom network.
\end{abstract}

Keywords-Long Term Evolution (LTE); microstrip; dual band; u-slot

\section{INTRODUCTION}

Microstrip Patch Antenna (MPA) is the most popular antenna in today's wireless transmission technology due to its incomparable characteristics. Microstrip antenna is embodiment of a conducting patch normally copper on a dielectric material having a ground plane on the other side. The microstrip antenna has the luxury of being low profile, lowpriced, easy to fabricate and modify, flexible in shape with rectangular, circular, triangular, elliptical or any shape needed, and can support dual or multiband frequency operation providing linear or circular polarization [1].

The Dual Band characteristic of microstrip patch antenna with u-slot has been established by many authors [2]. In this research work a microstrip dual band antenna is developed which consists of a rectangular patch on top of the dielectric substrate and over which a $\mathrm{u}$-shaped slot has been cut to create dual band antenna.

Long term evolution (LTE) is the cutting edge technology introduced in the wireless communication system to be the next big thing for at least ten years from now on. LTE is the successor of the third generation technology of 3GPP by fulfilling the requirement of fourth generation. LTE provides broadband internet in cellular or any devices. LTE data speed is ten times faster than existing third generation technologies. The two main advantages of LTE are that it covers more area and provide faster speed in wireless environment. Users of LTE don't need to be at home or office to experience broadband internet, just needed to be in the LTE coverage area [3].

LTE have many bands; where bands 1 to 31 are Frequency Division Duplex (FDD) and 33 to 48 and above are Time division duplex (TDD). The most used bands of LTE are LTE3 and LTE-7 [3]. A single element antenna covering these two bands gives coverage to the most of the telecom world and will support roaming and discard the need of using two antennas, hence reducing size of the device.

In recent days LTE supported technologies are being implemented globally and therefore, the need of antennas supporting LTE bands are increasing day by day. From this perspective, designing an antenna that will support two different LTE bands will allow roaming in different parts of the world which is much needed. Networks using the LTE-3 and LTE-7 bands will be available in ITU region 1, $2 \& 3$ and they are already employed in most of the developed countries [3]. The goal of this proposed work is to design and simulate a single element dual-band micro-strip antenna for LTE-3 and LTE-7 bands which can be used in near future for roaming.

\section{LITERATURE REVIEW}

Extensive research is ongoing to develop single element microstrip antenna with multiband operation. The antenna proposed in [4], [5] cover only one band either LTE-3 or LTE7 , although some of them are multiband or dual band. The antenna dimensions in [6]-[9] are considerably large. The geometry of the antenna proposed in [10]-[11] is quite complex and can only be used in base stations. The VSWR reference value taken [12] is 2.75 which is not good. The literature review facilitates the knowledge of the current available antenna literatures dealing with LTE-3 and LTE-7 bands. There is room available to improve the performance of the antenna through developing an antenna which covers both LTE-3 and LTE-7 bands with good return loss, small and simple geometry and ease of fabrication. 


\section{ANTENNA Design METHODOlOGY} below:

Overall methodology in designing the antenna is given

Step 1: Developing a single band antenna.

Step 2: Simulation of the single band antenna.

Step 3: Introducing u-slot to obtain dual band operation.

Step 4: Simulation of the dual band antenna.

Step 5: Finalizing the dual band antenna.

\section{DESIGN OF THE SINGLE BAND MPA}

A microstrip single band antenna consists of a rectangular patch on top of the dielectric substrate. In designing the antenna, Roger Corporations substrate RT Duroid 5880 with dielectric constant 2.2 is used. The length and width of the patch are determined by using (1)-(5) [13].

$$
W=\frac{C}{2 f_{r}} \sqrt{\frac{2}{\varepsilon_{r}+1}}
$$

Where, $\mathrm{C}=$ Velocity of Light

Effective dielectric constant is given by,

$$
\varepsilon_{\text {eff }}=\frac{\varepsilon_{r}+1}{2}+\frac{\varepsilon_{r}-1}{2}\left(1+\frac{10 h}{W}\right)
$$

Where,

$\varepsilon_{\text {eff }}=$ Effective dielectric constant,

$\varepsilon_{r}=$ Dielectric constant of substrate,

$\mathrm{h}=$ Height of dielectric substrate,

$\mathrm{W}=$ Width of the patch.

For a given resonance frequency $\mathrm{f}_{\mathrm{r}}$, the effective length is given by,

$$
L_{e f f}=\frac{C}{2 f_{r} \sqrt{\epsilon_{e f f}}}
$$

The actual length of the patch is given by,

$$
L=L_{e f f}-\Delta l
$$

Where,

$$
\Delta L=0.412 h \frac{\left(\varepsilon_{r}+0.3\right)\left(\frac{W}{h}+0.264\right)}{\left(\varepsilon_{r}-0.258\right)\left(\frac{W}{h}+0.8\right)}
$$

Using the above formulas and using a dielectric constant of $\varepsilon r=2.2$, with thickness of the substrate of $1.6 \mathrm{~mm}$, the geometry of single element single band microstrip antenna is shown in Fig. 1 and the basic parameters are given in Table 1 .

The return loss of the single band antenna is given in Fig. 2 and it can be seen that the antenna resonates at $1.75 \mathrm{GHz}$ and operating with return loss value less than $-10 \mathrm{~dB}$.
TABLE I. Proposed DuAlband ANTENNA DimENSION

\begin{tabular}{|l|l|}
\hline Parameters & Value \\
\hline Frequency (f) & $1.8 \mathrm{GHz}$ \\
\hline Substrate Thickness & $1.6 \mathrm{~mm}$ \\
\hline Dielectric Constant & 2.2 \\
\hline Length (L) & 65.8808 \\
\hline Width (W) & 71.05 \\
\hline Polarisation & Linear \\
\hline Probe Fed Position (F) & $29.9404 \mathrm{~mm}$ \\
\hline & \multicolumn{1}{|c|}{$\mathbf{F}$} \\
\hline
\end{tabular}

Fig. 1. Antenna geometry.

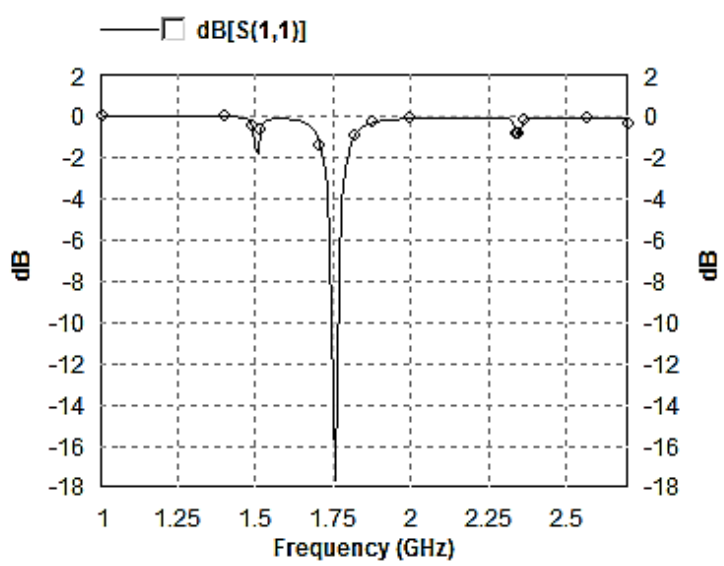

Fig. 2. Return loss Vs. Frequency of single band antenna.

\section{ANTENNA CONFIGURATION}

The dual band microstrip antenna is developed by cutting the slots of different shapes like U-slot, V-slot, pair of rectangular slots and step slots, etc. Hence the antenna designers need to adjust the dimensions and the position of the slots. The geometry of the dual band rectangular microstrip antenna is shown in Fig. 3. It is constructed on the substrate having dielectric constant $\left(\varepsilon_{\mathrm{r}}\right) 2.2$ and thickness (h) $1.6 \mathrm{~mm}$. The dimensions of the proposed dual band antenna are given in Table 2 and the geometry of the proposed antenna given in Fig. 3. 
TABLE II. PROPOSED DUALBAND ANTENNA DIMENSION

\begin{tabular}{|l|l|}
\hline Parameters & Value(mm) \\
\hline Length (L) & 65.8808 \\
\hline Width (W) & 71.05 \\
\hline Slot Length Horizontal (Ls) & 44 \\
\hline Slot length Vertical (Ws) & 40 \\
\hline Slot Thickness (t) & 2.5 \\
\hline Probe fed position (F) & \\
\hline & \\
\hline
\end{tabular}

Fig. 3. Antenna geometry.

The proposed structure is simulated using IE3D ZELAND software. After getting the geometry of single band antenna, slots are cut in the geometry to achieve dual band operation. Then, from the simulation, a result is achieved which is not necessarily good enough for resonant frequency. As a consequence, optimization on the dual band geometry is applied. After the optimization process, it can be observed that the antenna work suitably for the desired resonant frequencies.

\section{Simulation Results AND Discussion}

\section{A. Return Loss Plot}

The reflected power of an antenna is determined from the value of the antenna return loss. The return loss, S11 plot of the dual band antenna is given in Fig. 4. The s11 parameter value of dual band antenna is below -10dB at both LTE-3 and LTE-7 bands. The antenna is resonant at $1.88 \mathrm{GHz}$ and $2.55 \mathrm{GHz}$. Antenna is observed to be transmitting more than ninety percent of the excited power.

The VSWR value of the proposed antenna is given in Fig. 5 where it can be seen that the value is between 1 and 2 in both bands meaning that the antenna operates efficiently in LTE-3 and LTE-7 bands.

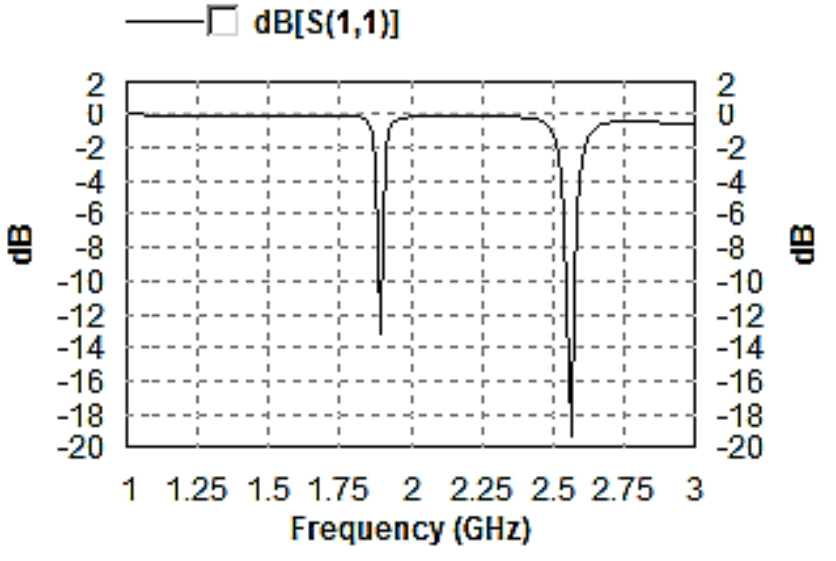

Fig. 4. Return loss Vs. Frequency plot of dual band antenna.

\section{B. VSWR Plot}

VSWR shows how much power is reflected back from the antenna towards the source. If the VSWR value is 1 that means all of the given power to the antenna is transmitted. An antenna will be considered a good one if its VSWR value is between 1 and 2. Antenna with VSWR value greater than 2 is not a good antenna.

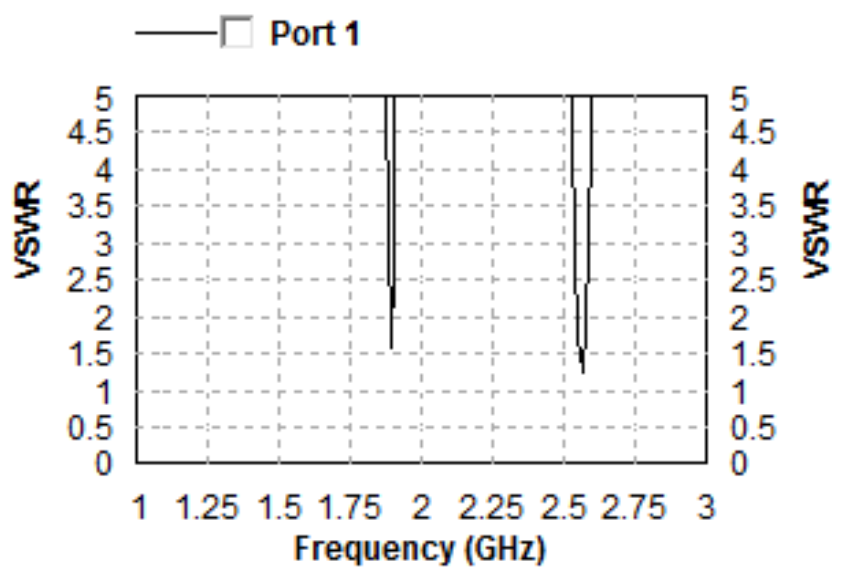

Fig. 5. VSWR vs. Frequency plot of the dual band antenna.

\section{Average Current Distribution}

The average current distribution provides the information about radiating side and non-radiating side of the antenna. Typically, antenna resonance occurs at half wavelength length. The current distribution of the microstrip antenna is known to be congested in the middle and gradually lesser at edges of the patch. The congested current can be seen by yellowish color in the middle, where the antenna is excited by the probe fed and less current density at the border of the patch indicated by the blue color. The radiating side and non-radiating side are also known to be acting as length and width, respectively. 


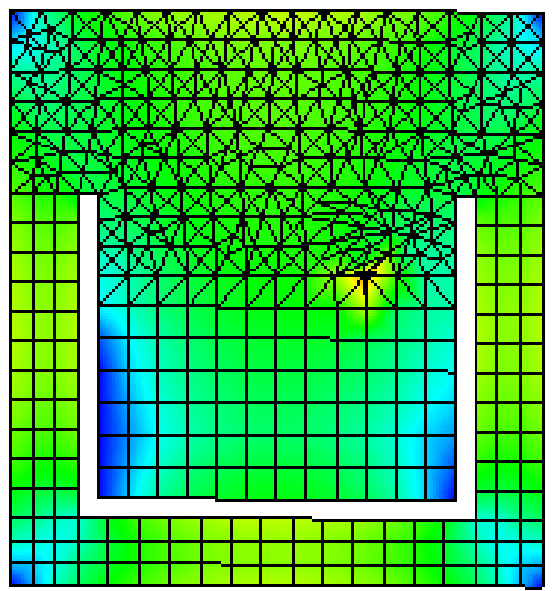

Fig. 6. Average current distribution at $1.88 \mathrm{GHz}$.

The average current distribution in Fig. 6 shows that the antenna is working with maximum congested current at the middle of the vertical side of the patch except at the corners of the patch. This gives the information that the vertical side is the radiating side of the basic single element MPA.

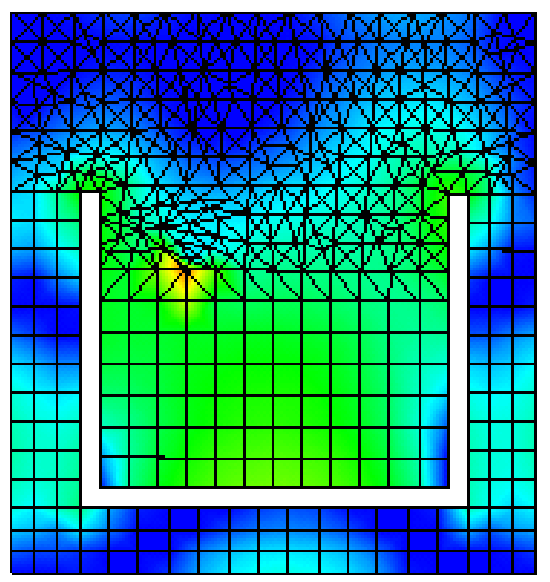

Fig. 7. Average current distribution at $2.55 \mathrm{GHz}$.

Fig. 7 shows that at the second band of $2.55 \mathrm{GHz}$, the slot edges produce the radiation with maximum current distributed inside the two arm of u-slot.

\section{Vector Current Distribution}

Vector current distribution provides the information about the distribution and flow direction of the current on the conductor patch. The polarization of the antenna can easily be seen from the information provided by the vector current distribution. In Fig. 8, the polarization of the antenna is clearly linear polarization as current follows a linear path on the surface of the conductor. And the maximum current is found to be congested in the middle of the antenna and minimum at the border of the conductor. This figure represents the vector current distribution of the dual band antenna at $1.88 \mathrm{GHz}$.

And in Fig. 9 the vector current distribution shows that the current is mainly distributed around the two arms of the u-slot with current flowing shows that the polarization of the MPA at $2.66 \mathrm{GHz}$ is nonlinear polarization.

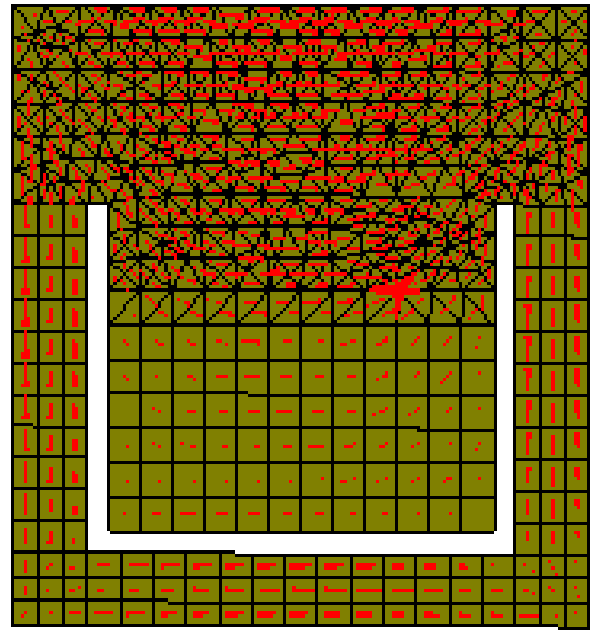

Fig. 8. Vector current distribution at $1.88 \mathrm{GHz}$.

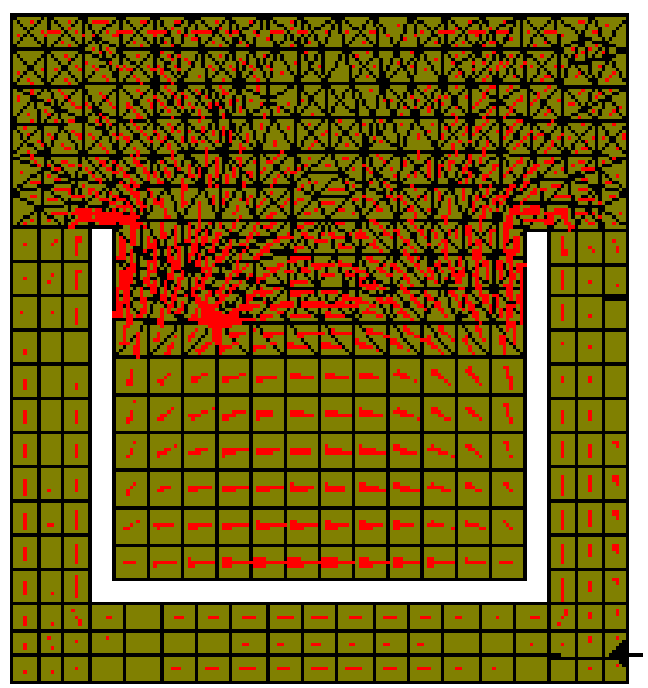

Fig. 9. Vector current distribution at 2.55GHz.

\section{E. 2D Radiation Pattern}

The necessity of 2D radiation pattern arises due to its vital role to grasp how the antenna is radiating in 3D. The 3D radiation pattern cannot be properly shown on a $2 \mathrm{D}$ surface. So it is very important to show how the antenna is radiating in $2 \mathrm{D}$ to perceive how it is actually radiating in 3D surface. In 2D radiation pattern of microstrip antenna, there will be no radiation in lower half and the radiation should be half circular as $2 \mathrm{D}$ radiation pattern takes 0 -degree and 90 -degree to show its radiation beam width.

2D radiation pattern of dual band in Fig. 10 and 11 are almost the same indicating that proposed antenna provides a good radiation pattern. The radiation of the proposed antenna is nearly half circular which is quite good. There is no radiation in lower half as the ground plane attenuates the signal downwards. The $2 \mathrm{D}$ radiation pattern of microstrip patch antenna should be half circular and no radiation should exist in underneath, this characteristic gives microstrip antenna advantage when the antenna is incorporated with printed circuit board. 


\section{$\longrightarrow-\Gamma \mathrm{f} 11,3, \mathrm{f}=1.88(\mathrm{GHz}), \mathrm{E}-\mathrm{total}, \mathrm{phi}=\mathbf{0}(\mathrm{deg})$ \\ $\longrightarrow-\Gamma \mathrm{f} 11,3, \mathrm{f}=1.88(\mathrm{GHz}), \mathrm{E}$-total, phi $=90$ (deg)}

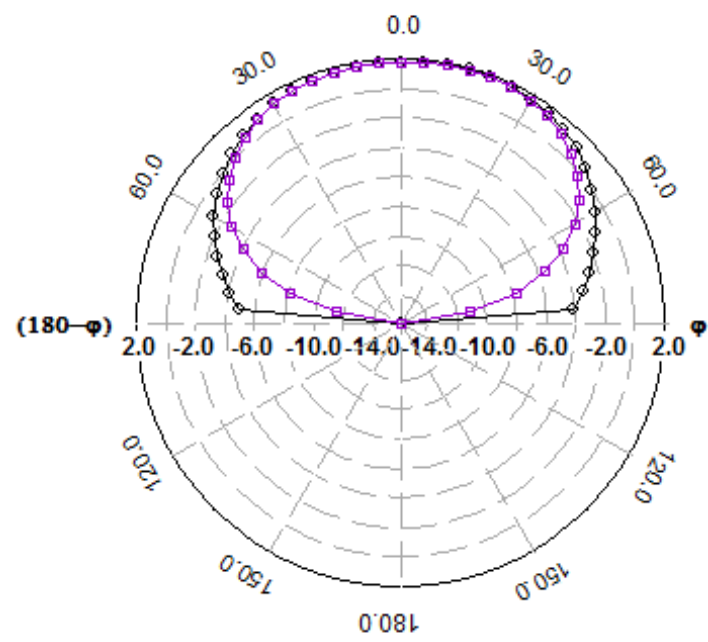

Elevation Pattern Gain Display (dBi)

Fig. 10. 2D Radiation Pattern at $1.88 \mathrm{GHz}$.
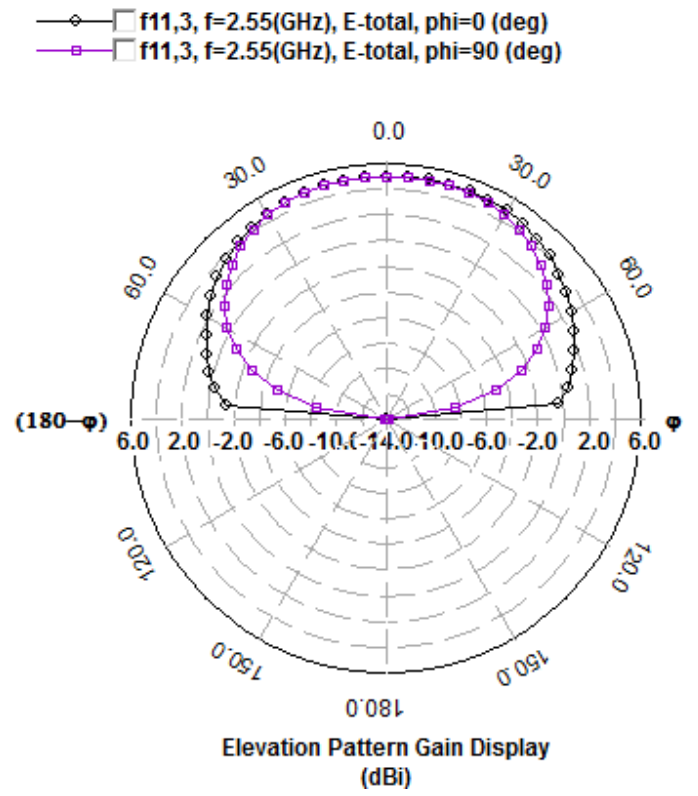

Fig. 11. 2D Radiation Pattern at $2.55 \mathrm{GHz}$.

\section{F. Final Results}

The final results of the propose antenna are given in Table 3. Proposed antenna shows good return loss at both LTE3 and LTE-7 bands with S11 values less than $10 \mathrm{~dB}$. The VSWR of the proposed antenna is less than 1.75 in both bands which describe that the antenna reflects less than 10 percent of the given power while radiating more than 90 percent. The gain of the antenna is in conformity to work perfectly and directivity of the proposed antenna shows that it has a good directional performance. Antenna efficiency is very good at both resonant frequencies having around 74 percent at LTE-3 and $84 \%$ in LTE-7. Also the radiation efficiency of the designed antenna is nearly 80 percent in both LTE-3 and LTE-7 bands.
TABLE III. FINAL RESUlTS OF THE PROPOSED ANTENNA

\begin{tabular}{|l|l|l|l|}
\hline Parameters & Value & Value & Standard Value [13] \\
\hline Resonate frequency & $1.88 \mathrm{GHz}$ & $2.55 \mathrm{GHz}$ & As per need \\
\hline Returnloss (S11) & $-12 \mathrm{~dB}$ & $-15.6 \mathrm{~dB}$ & Below -10db \\
\hline VSWR & 1.73 & 1.41 & Less than 2 \\
\hline Gain & $4.48 \mathrm{dBi}$ & $5.17 \mathrm{dBi}$ & $6-9 \mathrm{dBi}$ for MPA \\
\hline Directivity (dBi) & $5.82 \mathrm{dBi}$ & $5.93 \mathrm{dBi}$ & $5-8 \mathrm{dBi}$ for MPA \\
\hline Antenna Efficiency & $73.78 \%$ & $83.97 \%$ & $70 \%$ \\
\hline Radiation Efficiency & $79.65 \%$ & $86.86 \%$ & $70 \%$ \\
\hline
\end{tabular}

\section{CONCLUSION}

A dual band u-slot microstrip antenna for LTE-3 and LTE7 bands has been successfully designed in a single patch with $50 \Omega$ probe feed. The antenna simulation gives us dual band LTE-3 and LTE-7 operations with return loss below -10dB. The VSWR value of the simulated antenna is less than 1.75 which is in conformity with standard values; which means that the antenna operates efficiently with reflected power of less than ten percent. Antenna performance efficiency is nearly $80 \%$ in both bands and the antenna is properly working in the designated bands of LTE-3 and LTE-7 which are $1.8 \mathrm{GHz}$ and 2.6GHz. The designed and simulated antenna is unique in feature of its dual band characteristics because it operates in LTE-3 and LTE-7. Although there are some multiband antennas which cover two bands, there is hardly any dual band antenna which covers only these two bands.

\section{REFERENCES}

[1] Anuj Mehta, "Microstrip Antenna", International Journal of Scientific \& Technology Research, Volume 4, Issue 03, March 2015.

[2] R. Bhalla1 and L. Shafai, "Resonance Behavior Of Single U-slot Microstrip Patch Antenna", Microwave and Optical Technology Letters, 2002.

[3] Christopher Cox, "An Introduction to LTE: LTE, LTE-Advanced, SAE and 4G Mobile Communications", wiley and son 1td, 2012

[4] Habib M.S., Rafiqul I.M., Abdullah K., Jakpar M.J, "U-Slot Rectangular Patch Antenna for Dual Band Application." In: Sulaiman H., Othman M., Othman M., Rahim Y., Pee N. (eds) Advanced Computer and Communication Engineering Technology. Lecture Notes in Electrical Engineering, vol 315. Springer, Cham(2015),

[5] M. O. Katie, M. F. Jamlos, H. Lago and S. S. AL-Bawri, "Slots-loaded dual-band elliptical polarized antenna," IEEE International RF and Microwave Conference (RFM), Kuching, pp. 190-193, 2015

[6] W. S. Chen, Y. Chi, F. S. Chang and C. Y. Hsu, "Coupled-fed LTE antenna design for tablet applications," 2016 IEEE 5th Asia-Pacific Conference on Antennas and Propagation (APCAP), Kaohsiung, pp. 141-142, 2016.

[7] H. W. Badri, H. Zairi and A. Gharsallah, "Design of a Dual-Band antenna for GSM, UMTS, WLAN, LTE and Wi-MAX applications," IEEE 15th Mediterranean Microwave Symposium (MMS), Lecce, pp. 13, 2015.

[8] M. Madani Fadoul, T. A. Rahman, and A. Moradikordalivand, "Novel Planar Antenna for Long Term Evolution (LTE)," International Journal of Information and Electronics Engineering vol. 4, no. 1, pp. 59-61, 2014.

[9] Md. H. Haroun, HAyad, J. Jomaa "Design a tri-band Microstrip slot antenna for LTE applications," 978-1-4799-4129-2/15/\$31@2015 IEEE

[10] J. Zhang, X. Q. Lin, L. Y. Nie, J. W. Yu and Y. Fan, "Wideband DualPolarization Patch Antenna Array With Parallel Strip Line Balun 
Feeding," in IEEE Antennas and Wireless Propagation Letters, vol. 15, no., pp. 1499-1501, 2016.

[11] Y. Cui, F. Li, Y. Pan, Y. Fan and R. Li, "A novel dual-polarized broadband planar antenna for base stations," 2015 IEEE International Symposium on Antennas and Propagation \& USNC/URSI National Radio Science Meeting, Vancouver, BC, 2015, pp. 1964-1965.
[12] F. Ahmed, Y. Feng, R. Li “A Multiband Multiple-input Multiple-output Antenna System for Long Term Evolution and Wireless Local Area Networks Handsets," IJE TRANSACTIONS B: Applications Vol. 29, No. 8, (August 2016).

[13] Balanis, Constantine A. Antenna Theory: Analysis and Design. Hoboken, NJ: John Wiley, 2005. 